\title{
Scientific Journals in the Data-Driven Era
}

\author{
https://doi.org/10.19195/1899-5101.13.1(25).8
}

The rise of new media and technologies followed by the increasing distribution of information via social networks has changed scientific journals, furthermore their overall structures and organizational systems. The development of social media tools, such as Academia.edu, LinkedIn and ResearchGate and data-driven platforms, such as Google Scholar, further offer new opportunities for visibility and findability of scientific research. Scientific journals need to adapt and evolve to make an impact on the fast-changing information society.

Here, at the Central European Journal of Communication, we have gone a long way in constantly adjusting our work. To draw on future CEJC strategies we invited our colleagues from other journals to discuss the state-of-the-art alongside challenges for scientific journals in the data-driven age. The roundtable discussion took place on November 19th, 2018, in Wrocław during the anniversary conference, entitled "Central European Journal of Communication 10 Years On".

Below we present a transcript of selected ideas presented during the meeting in Wrockaw. The goal of the session was to map the biggest challenges and strategic goals for the scientific journals to go forward. Michał Głowacki (Central European Journal of Communication) invited journal editors to discuss both challenges and opportunities concerning three key themes: scientific journals and the digital age, maintaining quality in the data-driven era and strategies for the following years. The session was attended by Andrzej Adamski (Media - Teologia - Kultura), Michał Bukowski (Zeszyty Prasoznawcze), Marton Demeter (KOME. An International Journal of Pure Communication Inquiry), Katarzyna Konarska (Dziennikarstwo i Media), Michał Kuś (European Journalism Observatory), Małgorzata Madej (Wrocławskie Studia Politologiczne) and Anna Mierzecka (Studia Medioznawcze). The ideas presented in 2018 helped us to draw up our internal strategy for the CEJC in 2020-2022.

Michał Głowacki: One of the consequences of the rise of social media is that we need to be in a place where people are. Our traditional journal websites might be insufficient to disseminate scientific research. What is your experience with new and high technologies for research dissemination?

Marton Demeter: I think that scholars are 'dinosaurs' in that sense; they don't use social media, such as Facebook sites for journals and academic process. There is an 
old and prestigious journal, Journalism and Mass Communication Quarterly, which started a Twitter campaign with a rather small impact. I think that most scholars don't use social media for academic purposes. On the other hand, they take care of quality metrics and databases which in turn measures the impact of researchers. But sometimes they also need you to make their research popular; this is what we call 'science communication' - you make a popular summary of your research. I don't think the wider Facebook community is interested in scientific research blogs.

Anna Mierzecka: There are platforms such as ResearchGate, Web of Science, or SCOPUS, where I look for relevant academic literature. But to be updated I need to follow the profiles of scientific topics and follow all the people I am interested in. I also started my Twitter account. I saw Journals publishing their recent articles via Twitter. It is a different type of communication; it's easier to scroll and browse. I know that Twitter is widely used during international conferences, but not in Poland, right?

Andrzej Adamski: A couple of years back we conducted a research project entitled "The interfaces of science in the post-digital age". We conducted around twenty in-depth interviews with researchers from Slovakia, Czech Republic, and Poland. Some of the questions we addressed were about new technologies and online journals. For instance, we asked, "What do you think about academic journals published online?" Also "Do you think that your research discipline is missing a multimedia journal?" We observed a great level of openness and enthusiasm from young scholars. But older researchers were more traditional. I think that new technologies give us a chance to go across some traditional thinking. Scientific practice on the internet can be something more than text or graphic illustrations. Look at the examples of journals from medicine, they use online movies and interactive multimedia presentations to support their digital moves.

Michał Kuś: One of the key things is the mindset and thinking. Generally, we all operate in a very specific and specialized research field. The most important thing is, therefore, to address research outcomes mostly to those who might be interested. For instance, on Twitter, I see a lot of posts about news on the publication of the journal's next issue and this is often connected with personal recommendations for other profiles to follow. I think this type of activism works well and the targeting issues are crucial.

Michał Bukowski: I think I have a slightly different perspective. I do not have personal experience with using social media and new technologies as a publisher. I think we should distinguish between a publisher's perspective and the user or researcher's perspective. For me, it is obvious that all researchers, all users use those news technologies, because they are efficient. But as a publisher, I am quite reluctant to go into social media, because they are not politically neutral for me. 
Małgorzata Madej: Agreed. I just want to highlight the differences between researchers, leaders, and publishers. Because, as you mentioned, social media like Facebook are more difficult to target and they are more specific. There might be a need for considering social responsibility in the times of fake news and promoting scientific knowledge also in the context of the broader audience. However, I think as scientists, we need to create a border, a clear frontier between general communication, the general public and our professional networks.

\section{Michał Głowacki: And Open Access?}

Marton Demeter: We already publish online only and online first papers. I think that all the most prestigious journals have a similar strategy.

Małgorzata Madej: I truly believe that online-only is a very convenient solution for communicating, distributing, and promoting the journal's publications. I think that this is the only way to survive for future scientific publications. Having everything online is much more convenient to use in practice. So, generally, I think this is an excellent solution.

Andrzej Adamski: The idea of open access is also very important because we have a large group of so-called predatory journals that are very aggressive in their advertising. I do not know everything about all fake news or fake articles, or maybe articles generated by some algorithms, if you pay. I think we must publish everything online, we must deliver good publications to deliver true information to society.

Michał Kuś: As an online platform with the aim of delivering scientific research all the texts at the European Journalism Observatory are published online for free. Publishing processes in some journals take a quite long time, and this is something that harms the paper's quality; once it is published, it is already outdated. And that's the challenge for all of us.

\section{Michał Głowacki: Abstracts, indexes and impact factors have become an import- ant part of our work. Do you have any quality models to follow?}

Marton Demeter: Yes, we have to keep an eye on the citations indexed and this is related to the journal's quality. For instance, if you want to be indexed in the Web of Science, you need citations from journals that are already indexed. So basically, you have to cite at least one article from these journals and you have to do it systematically.

Ania Mierzecka: One of the problems is that we represent social science and our research topics are mostly regional. For instance, If I write something specifically for Poland, I lose a chance to be quoted because of the scope of the research. So, 
I don't have a recipe on how we could support each other. And I think this invisible university cooperation could help us with that.

Katarzyna Konarska: Our debate about the journal is about both traditional and online versions. But nowadays we are facing a big problem. The goal is to find out what we should do to adapt.

Michał Bukowski: Yes. I can add something to that. The most important thing is to be in touch with our readers, including our potential authors. I was thinking about that double task strategy in terms of, for example, a local theatre. You just want to provide a good performance to a limited number of audiences. And this is your goal. And this is what you should be focused on.

Michał Glowacki: This local theatre perspective sounds interesting. And how about challenges for being indexed in the international scientific database? Is being a part of the international publishing group a part of the strategy?

Marton Demeter: Some Western publishers wanted to buy up our journal. The price is not high enough, so my colleagues don't want to sell it. But there was the case of Javnost/The Public as soon as the journal was indexed by the Web of Science.

Małgorzata Madej: I think that collaboration with international publishers creates risks and challenges. I think I would rather play a role in the local theatre and fight with the very few possibilities on Broadway. But on the other hand, I think we can compete obviously to get into the market, into the Web of Science and other important databases. This is a difficult task. We can say that older, more established journals hold an advantage over us because they are already a part of the system. But I believe we shouldn't give up to and try to be a part of it.

Michał Głowacki: There are many scientific journals offering insights to qualitative and quantitative analyzes that policymakers, media owners and managers could take advantage of. What role shall we play to have a potential impact on our network communities?

Michał Kuś: Here at the European Journalism Observatory we sometimes find it difficult to convince researchers and academics to prepare pieces addressed to a wider range of stakeholders. Generally, researchers are involved in so many different activities, such as teaching, writing papers, organizing conferences, and so on. Sometimes we also volunteer during the night. That is not probably because we believe it is our mission to support different initiatives. There are examples of universities that use academic journals as an important tool for their branding strategy. But I do not see this happening in Poland. 
Anna Mierzecka: So, I agree with every word; there are only a few practices like that in Poland. SWPS has its podcast available on Spotify. It is not science, but this is rather a popular science. In Warsaw, there is also the Copernicus Scientific Centre with workshops addressed to different communities and examples of collaboration between scientists and people. I do not think that this is the primary role of academic journals. Another thing is that you need to have the right skills to communicate with your wider audiences.

Michat Bukowski: There used to be the branch of journalism which was called 'science journalism'. And these people shall be among the receivers of scientific research. But scientific language is sometimes a barrier for journalists. They look at our articles and they say: "Yes, this is interesting, but I don't understand it; the language is too difficult for us". Therefore, it is not an easy thing to distinguish between 'easiness' and 'scientific correctness'. And that's the goal for publishers to motivate authors to develop their works into more accessible pieces.

\section{Michał Głowacki: So, what are the key strategic points for the following years?}

Michał Bukowski: I think that for Zeszyty Prasoznawcze the question will be whether to become specialized or to maintain a more general way of publishing.

Małgorzata Madej: Obviously, each scientific journal has a specific situation and needs to respond to some specific circumstances. But I think that the problem of quality evaluation is about finding a strategic balance between what we want our journals to represent and how we want to shape the scientific reality. For instance, there is a problem of strategic balance between imposed international quality criteria vs. scientific reality. We are in the time of higher education reforms, so adopting this external reality is a challenge for us. We all know we need to make our work better, be better authors, be better reviewers, better adjustment to new communication tools, and so on. One of the questions is: How can we combine our mission with being very strictly quantified by the ministries, publishers, and universities?

Marton Demeter: I am not fully aware of the situation in Poland, but I suppose that the Hungarian case is similar. So, our strategy would be to find a Western publisher and continue our role as the journal's editors. I don't think that Western publishers are more professional in comparison with journals published in Central and Eastern Europe. But they have money, and this is very important.

Andrzej Adamski: Well, for doing the research... We need time, we need money, but we also need passion. And passion sometimes means that we work for free. 